\title{
Editorial
}

\section{Can the management of gonorrhoea be improved?}

This issue of Genitourinary Medicine contains papers on the epidemiological treatment of gonorrhoea by Carne and the diagnosis of oropharyngeal gonorrhoea by Barlow. These and others to follow are based on background papers commissioned for a series of workshops arranged jointly by the National Audit Development Project in Sexual Health and the Research Unit of the Royal College of Physicians. The project was funded by the NHS Executive in response to the Health of the Nation initiative, which in 1992 had identified gonorrhoea as a Key Area. At this time the prevalence of the infection was already starting to fall, but considerable regional differences in incidence were recognised. It was apparent that clinical practice should be led by and measured against evidence-based agreed guidelines. The formation of the Association for Genitourinary Medicine (AGUM) and the Genitourinary Nurses Association (GUNA) provided an excellent means of enlisting speciality-wide support for an audit and disseminating its findings, and further input was provided by the Society of Health Advisers in Sexually Transmitted Diseases (SHASTD), who in 1995 issued nationally agreed policies for good practice in partner notification.

All these groups participated in the workshops, whose first task was to set standards (which have now been published). ${ }^{12}$ The workshops agreed on aspects of practice that particularly required assessment and developed an audit questionnaire which, after piloting, was issued in late 1995. The intention was to study all cases of gonorrhoea diagnosed in the first three months of 1995 . Every clinic in the UK was contacted by post. Replies were received from $79 \%$, although some clinics were satellites or too small or recently established to have cases for audit. The number eventually contributing patients was $155,60 \%$ of the total. Clinics gave details of all patients diagnosed as having gonorrhoea during the study period up to a maximum of 30 patients, which resulted in 1308 patients being included, $59 \%$ of all cases reported to the Department of Health in the quarter.

Key findings of the audit are listed below; detailed results were sent to all clinics ${ }^{3}$

- Almost half of all cases of gonorrhoea are diagnosed in London.

- Homosexual males provide $32 \%$ of cases in London, $19 \%$ outside London.

- Black Afro-Carribeans provide up to $53 \%$ of cases (big London centres), $43 \%$ in big provincial centres, compared with $15 \%$ in small provincial clinics.

- Clinic microscopy can provide an immediate diagnosis and currently detects $89 \%$ of male urethral cases, but only $37 \%$ of female infections.

- Gonorrhoea is cured in $95 \%$ of patients with current regimes.

- Quinolones have now overtaken penicillins as the treatment most used in the UK.

- Patients report on average 1.5 contacts each, but overall only 0.5 contacts attend the clinics for examination; within this figure the rate attending big London clinics is half that attending small provincial clinics.

The findings of this first audit were reviewed in a final workshop, where it was possible to set realistic qualitative standards for future work. Figures were agreed for the accuracy of diagnostic microscopy and for the number of patients seeing the Health Adviser. The ethnic mix of gonorrhoea, even though ethnicity data was only available for $71 \%$ of cases, was cause for concern. It was agreed that further research needs to be done on the social, ethnic and biological factors involved in gonorrhoea, and new strategies developed for health promotion amongst black urban men. New work is already coming forward in this area, and in other areas identified by the audit as problematic: a systematic surveillance is being set up between London teaching hospitals which should identify the emergence of resistance to quinolones; and the problems of contact tracing, particularly in London, are being addressed by SHASTD with a view to better coordination between clinics.

\section{Evaluation}

In assessing this exercise it is worth evaluating both its methodological features and its effect on practice. Audits elsewhere have been criticised for the way in which samples have been obtained, for drawing retrospectively from patients notes which have been incorrectly coded, or being unable to find all relevant notes. In genitourinary medicine clinics, however, coding is performed systematically and usually by senior medical staff. The notes are kept within clinics and are readily retrieved. Case definition has been a problem in other specialities, but here we could do so precisely by insisting on culture confirmation of gonnorhoea (although this prevented us from assessing the accuracy of the laboratory in confirming all cases felt to be gonorrhoea on clinic microscopy). Another problem elsewhere has been sample size, and indeed with the falling prevalence of gonorrhoea this is a real limitation on local audits. However, by taking a national sample we were able to work with large numbers. Patients also came from a wide range of different settings. We suspected there would be differences between metropolitan and provincial clinics, and this did turn out to be the case for sexual orientation and ethnicity of patients, and for the outcome of contact tracing. To identify the causes of this difference, it would be desirable to have more data on case mix, such as socio-economic status, as well as more comprehensive ethnicity data.

A concept which has been slow to take root in some specialities is that of "clinical" audit, involving all the professions dealing with the patient. In genitourinary medicine clinics this concept of a service being provided by the whole clinical team has been central to practice for years ${ }^{4}$ and for most activities auditing the work of doctors in isolation would have little meaning. In this audit, nurses and health advisers took part in developing the standards, 
designing the questionnaire and completing it. Involving different professional groups was also important in disseminating and implementing the findings of the study. Finally, with a speciality that addresses sexually transmitted infections, it is particularly important that improvements occur evenly: the most important outcomes are national, concerning the prevalence of disease in the community. This is recognised by clinicians in the speciality, who contributed willingly to this audit. Individual components of a national service may function well but, as has recently been shown with the National Coordinating Network for cytology screening, ${ }^{5}$ it may be only when there are explicit national arrangements that best results are obtained.

\section{Acceptability and effectiveness}

It was recently stated ${ }^{6}$ that audit has failed to win the hearts and minds of the medical profession. Its ultimate aim is to improve the quality of service, but to an active clinician feeling he is working as hard and as well as is humanly possible, this sounds like a management mantra of no personal relevance. The problems are three fold: identifying areas where change should occur, believing that changes will occur, and incorporating the process of assessment and response into routine practice. As described above, this audit has both identified areas where change is desirable and provided stimulus for measures to address them. Many of these changes will be incremental and multi-factorial. For example, standards for microscopy are important but may well be affected by changes in diagnostic tests. Contact tracing is particularly challenging and, as it is central to the status and identity of genitourinary medicine, it needs to be addressed. For example, if it could be proved that seeing the health adviser leads to more contacts being identified, then more resources should be put into health advising. This in turn raises the issue of accountability. Clinicians should be willing to alter or improve their practice as a result of audit and repeating audit will show whether this has occurred, but when the blocks to improvement are lack of provision of resources then audit will only be supported if there is some prospect that it will influence future funding.

Agreeing measures, and applying them in a national audit was the only way in which the extent of the challenge in partner notification could be identified. Previous studies had been local and qualitative. Generally, it is clear that for audit to function as a means of continual improvement of practice, there needs to be systematic prospective collection of data on which audit may be based rather than intermittent retrospective studies. ${ }^{6}$ The minimum data set can be progressively refined so that is simple enough to collect routinely. For example, this study makes it seem likely that all clinics should collect ethnicity data at least until the next national audit is done; and with another study we could determine whether collecting patients' occupations was worthwhile. As a result of the work of this project we have clear evidence-based guidelines so we know what we should be doing. We have some outcomes, and we have an audit instrument, so we can re-audit our- $\mathbb{\Phi}$ selves. We should now make sure that achievable improvements are actually implemented.

The future-chlamydia

In the UK chlamydia is currently emerging as the sexually $\overrightarrow{\vec{F}}$ transmitted infective organism where intervention could $\overrightarrow{0}$ produce the most significant results ${ }^{7}$ because of the huge $\frac{}{\bar{\sigma}}$ numbers of cases and because treatment in early infection $\bar{s}$ is easy and prevents later disease. It is more diagnosed $\stackrel{\mathbb{D}}{\triangle}$ outside genitourinary medicine practice than gonorrhoea $\%$ but the principles of management are identical. Policies $\vec{\circ}$ on population screening and use of diagnostic tests can be set by expert review and the Department of Health has set $\vec{\omega}$ up a working party to do so, but management standards on treatment, partner notification, and health promotion need to be developed in the real world of clinical practice, in which audit functions. I believe that national audits of $\omega$ chlamydia management would be supported by the spe- $\frac{\text { o }}{2}$ ciality of genitourinary medicine, whose practitioners are $\overrightarrow{ }$ generally proud of their work and their contribution to $\mathbb{8}$ combatting sexually transmitted diseases in the country as a whole, and I hope that the momentum of this first $\stackrel{\varrho}{2}$ national audit will be sustained.

I would like to thank the authors of the expert papers presented at the workshops; the Regional audit chairmen; the members of the Central Audit Group : Drs Pat Munday, Ratish Basu Roy, Angela Robinson, Derek Timmins, Jan Welch; Carol Bedford, Dorinda Thirlby, Gill Bell); and the Research Unit of the Royal College of Physicians and its director, Dr Anthony Hopkins.

MARK FITZGERALD,

Taunton and Somerset Hospital,

Musgrove Park, Taunton,

Somerset TA1 5DA, UK

Accepted for publication 2 December 1996

1 FitzGerald M, Bedford C. National standards for the management of gonorrhoea. Int $\mathcal{F}$ STD AIDS 1996;7:298-300

2 FitzGerald M, Thirlby D, Bell G, Bedford C. National standards for contact tracing in gonorrhoea. Int $\mathcal{F} S T D$ AIDS 1996;7:301.

3 FitzGerald M, Bedford C. The clinical management of gonorrhoea: results from the National Audit Development Project. Taunton: Central Audit Group in Genitourinary Medicine 1996

4 Allen I, Hogg D. Workroles and Responsibilities in GUM clinics. London: 은 Policy Studies Institute 1993:187-95.

5 Sasieni PD, Cuzick J, Lynch-Farmery E. Estimating the efficacy of screen- $\frac{D}{O}$ ing by auditing smear histories of women with and without cervical cancer. Brf Cancer 1996;73:1001-5.

6 Hopkins A. Clinical audit: time for a reappraisal? $\mathcal{F} R$ Coll Physicians London 1996;30:415-25.

7 Johnson AM, Grun L, Haines A. Controlling genital chlamydial infection. $B M \mathcal{F}$ 1996;313:1 160. 